\title{
STRUCTURE OF THE MARATHON BASIN (NE ATTICA, GREECE) BASED ON GRAVITY MEASUREMENTS
}

\author{
Chailas S. ${ }^{1}$, Tzanis A. ${ }^{1}$, and Lagios E. ${ }^{1}$ \\ ' Department of Geophysics - Geothermy, National and Kapodistrian University of Athens, \\ Panepistimiopoli,15784Zografou,Greece; schailas@geol.uoa.gr; atzanis@geol.uoa.gr; \\ lagios@geol.uoa.gr
}

\begin{abstract}
This work presents the results of a high resolution gravity survey conducted in the area of Marathon Basin to asses the structure of the basement. A total of 120 gravity stations were measured. Standard data reduction procedures were followed, albeit based on modern, high precision techniques. The inversion of the Bouguer anomaly map provided a rather detailed image of the basement topography completing the information available from surface geological and morphological surveys. The major structural features of the Marathon Basin appear to be controlled by a system of $N E-S W$ neotectonic faults causing stepwise $N W-S E$ deepening of the basement to a maximum detectable depth of $\sim 450 \mathrm{~m}$. These faults, together with a system of NW-SE major, and a host of minor faulting features, lend to the Basin characteristics of a Riedel structure formed by a predominantly $\mathrm{N}-\mathrm{S}$ extensional field effecting clockwise block rotation. This mode of deformation may also have facilitated the formation of local anticlinal/ synclinal structures, which endow the area with its rather complicated morphology. Finally, the multiple intersecting faults appear to form a permeable network, presumably responsible for the salination of the local aquifer system; the NE-SW major normal faults may the most significant contributor to this effect.
\end{abstract}

Key words: NE Attica, gravity modelling, Riedel structure.

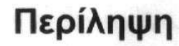

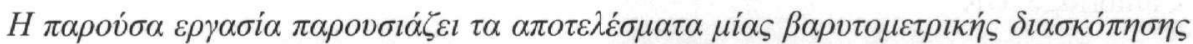

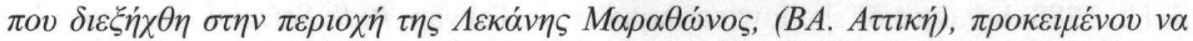

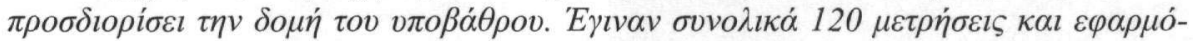

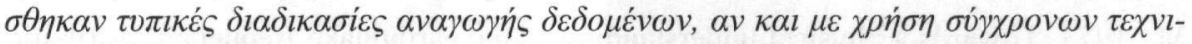

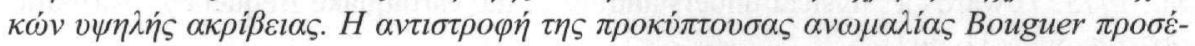

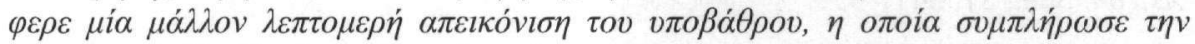

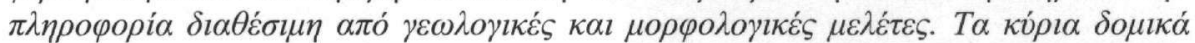

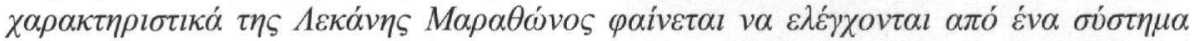

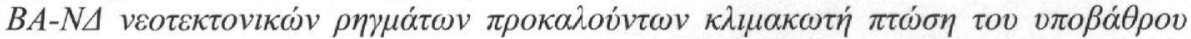

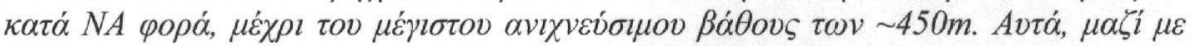

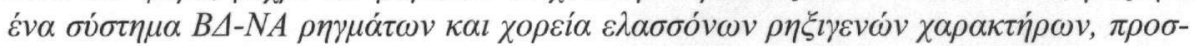

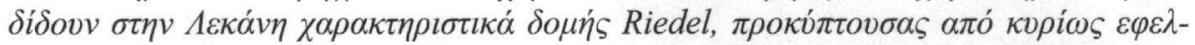

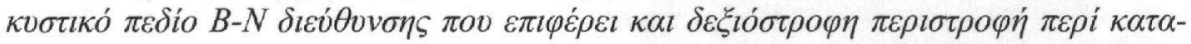

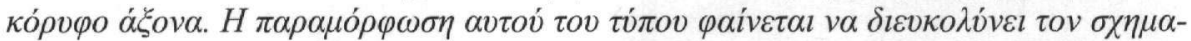

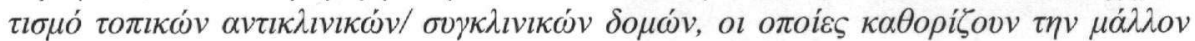




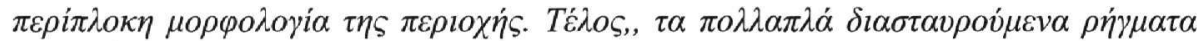

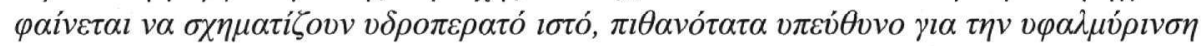

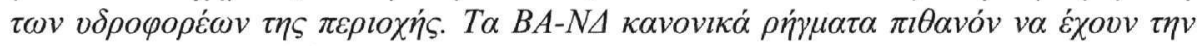

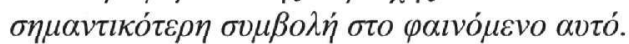

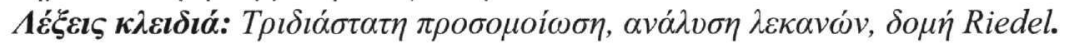

\section{Introduction}

This paper presents the results of a gravity survey conducted in the area of the Pleistocene Marathon Basin (NE Attica, Greece), as part of an extensive research programme to study the hydrogeological characteristics of the area. The main objective of the survey was to evaluate the depth and morphology of the basement, hence the macroscopic characteristics of the structures hosting the aquifer systems of the area. Moreover, and given that the aquifers experience intense salination, attributed by some authors to the permeable communication of the bedrock marbles with the sea (e.g. Stavropoulos and Tzima 2001, Margonis 2006), an additional objective was to evaluate the neotectonic structure in an attempt to understand the origin of such phenomena. Notably, this would also provide information about reverse pollution effects, i.e. data on the paths through which pollutants due to intense agricultural activity may be transported to the sea and to the nearby natural reserves of Schinias wetland and pine forest. Finally, the results of the survey may contribute to the understanding of the geology and tectonic evolution of the study area and, to a lesser extent, the regional geology and tectonics.

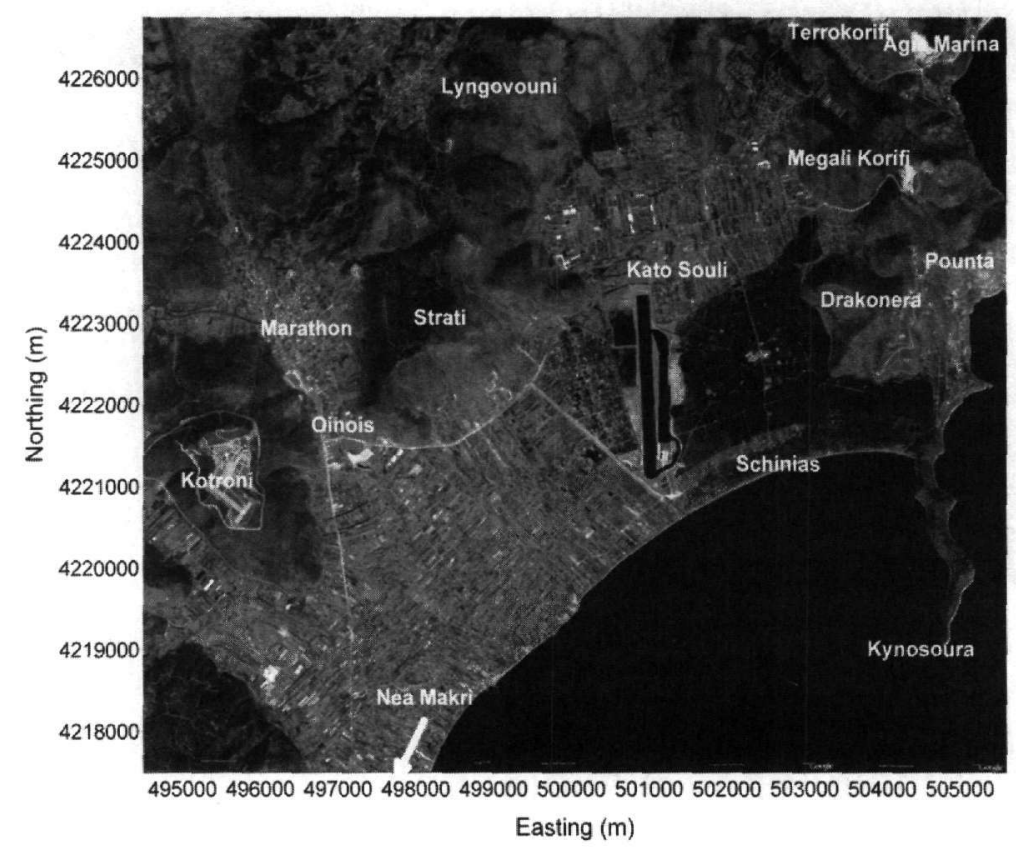

Figure 1- Satellite image and geography of the study area (retrieved from Google ${ }^{\mathrm{TM}}$ Earth)

The Marathon basin has an area of approximately $40 \mathrm{~km}^{2}$ and is shaped as a parallelogram with dimensions $9 \times 4.5 \mathrm{~km}$ and NE-SW oriented long axis. In the Marathon and Kato Souli plains the relief is very smooth, almost flat as can be seen in Figures 1 and 4 . The plains are bounded to the north by mounts Kotroni, Strati and Terokoryfi, to the west by the Penteliko mountain complex, to the south by Marathon bay and to the east by the Drakonera and Mytika uplands. The transition to the highlands coincides with abrupt topographic changes. 
The basin area has a well developed road network, suitable for the requirements of a gravity survey. This facilitated the establishment of 120 gravity stations, covering over $90 \%$ of the Marathon and Kato Souli plains with a linear density of approximately one station per $500 \mathrm{~m}$. This is expected to afford a rather high definition image of the basement topography (assuming that the scales of the apparent and buried structure(s) are similar).

\section{Geology and Tectonics}

The geology of the broader area surrounding the Marathon basin is detailed in a number of publications (e.g. Boetechtel and Papadeas 1968, Lozios 1991, 1993). In general, it is thought to represent a "relatively autochthonous" metamorphic sequence. The geomorphology, paleoenvironment and contemporary status of the Basin is also discussed by several authors (e.g. Maroukian et al. 1993, Margonis et al. 2002, Seni et al. 2004, Pavlopoulos et al. 2006). Herein, only a short description will be provided, suitable for the purposes of this presentation.

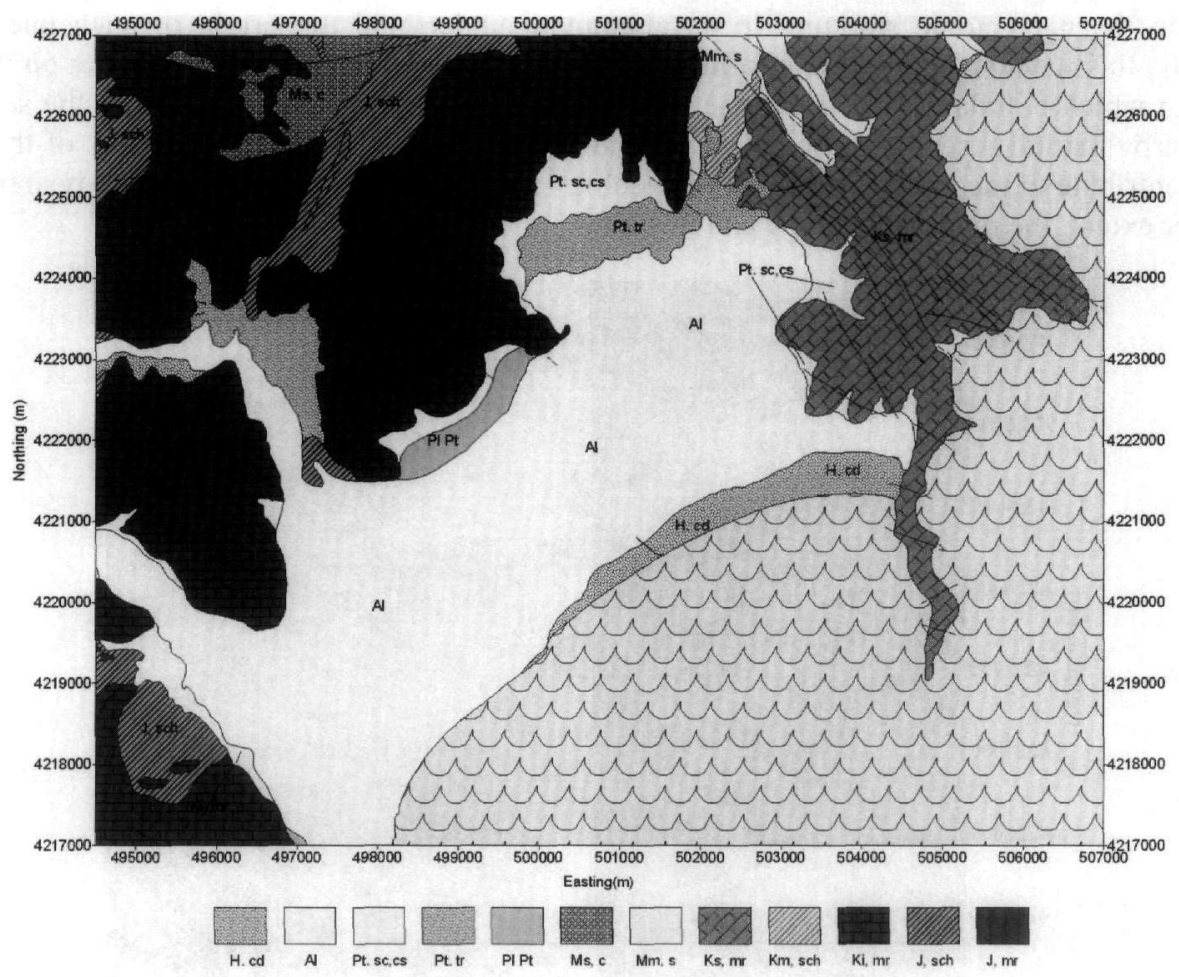

Figure 2 - Geological map of the area of Marathon basin area. Hed: Holocene coastal formations; al: Alluvial deposits; Pt.sc.cs: Pleistocene talus slopes; Pt.tr: Pleistocene terrestrial de-

posits; M.ms: middle-upper Miocene lacustrine deposits; Ks.mr: U. Cretaceous marbles; Km.sch: Ramnounta schists; Ki.mr: L. Cretaceous marbles; J,sch: schists (mainly mica and chlorite) with quartzofeldspathic rocks and metabasites;. The figure is based on the 1:50000 standard issue geological map published by the Institute of Geological and Mining Exploration (IGME)

The Marathon basin is filled with post-Alpine formations developing in a NE-SW direction along the coastal area from Nea Makri to Schinias and extending northwards, up to the archaeological site of Ramnous. According to Mettos (1992) and Lozios (1993), these consist of Quaternary alluvial deposits with significant at places thickness, terrestrial sediments, detritus (talus slopes) and beach rock (Fig. 2). 
The post-Alpine formations rest unconformably on the Mesozoic (Late Triassic - Late Cretaceous) metamorphic basement rocks outcropping at the margins of the Basin. Lozios (1993) distinguishes the following lithological units: the Ano Souli - Agioi Theodori schists; the Agios Dimitrios Terokoryfi marbles, the Ramnounta schists, the Agia Marina marbles and the Agia Marina schists.

The main faulting features of the study area have NE-SW and NW-SE orientations and delineate the boundaries of the major structural units of the study area (Fig. 2). In the study area, the NW-SE system is directly observable in the metamorphic basement, while the NE-SW faults are determinable by the intense morphological discontinuities and the colluvial deposits developing along their strike. The NE-SW fault system is generally believed to be older than the NW-SE system, which is also thought to be secondary, but according to Lozios, (1993), some important subsets of both systems appear, at least partially, contemporary in the broader area of Marathon Basin.

\section{Gravity Measurements and Data Reduction}

The main target of the gravity survey was to image the alpine basement, to determine the thickness of the post-Alpine sediments and to reveal the covered tectonic structure of the Marathon basin. One hundred and twenty (120) gravity stations were established in the area, distributed in such a way that the mean distance between any two neighbouring stations is approximately $500 \mathrm{~m}$. As shown in Figure 4, they are spread throughout the post-Alpine formations covering the Marathon and Kato Souli plains, while several stations are located on the metamorphic basement (uplands) to control the inversion and interpretation processes. This distribution may resolve with adequate precision, the geometry of the basin margins, thus providing clues as to their nature and origin; it may also resolve in detail the depth and topography of the basement under the pos-Alpine formations.

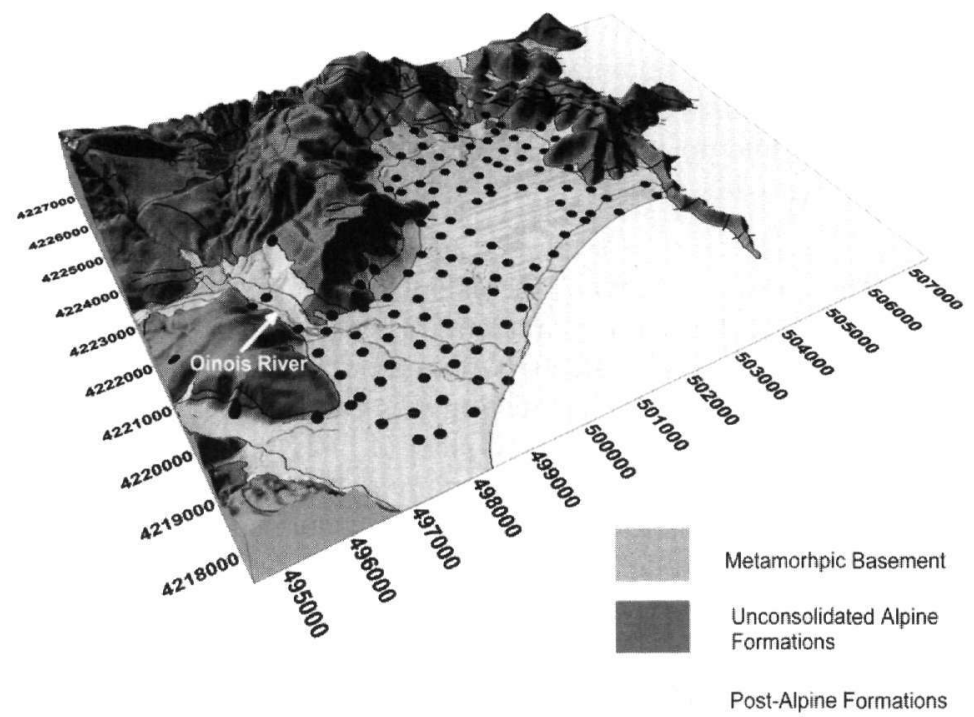

Figure 3 - The topography of the study area based on the DEM prepared for the present project with simplified geology. Overlaid is the distribution map of the gravity stations extending over post-Alpine deposits and the mountainous area (metamorphic basement). (Perspective view from SSW, coordinate axes in metres)

The typical measurement comprises a gravity-meter and GPS to precisely measure the station coordinates. The coordinates were referred to the Hellenic Geodetic Reference System (HGRS87 ); for each station the orthometric height was calculated (through a tie with a local triangulation 
pilar founded by the Hellenic Army Geographical Survey [HAGS]). Gravity and GPS observations were simultaneous at each station. Gravity measurements were taken with a LaCoste and Romberg Model $\mathrm{G}$ gravity meter. A local network consisting of eight base stations (serving both as gravity and GPS base stations) was established and used to control instrumental drift; the gravity values of the bases are referred to the IGSN'71 datum (Morelli et al. 1974) through a tie to a IGSN'71 station established at the Department of Geophysics \& Geothermy. Gravity observations were reduced for linear instrumental drift and elastic tide response; the latter was calculated after Cartwright and Tayler (1971), as modified by Cartwright and Edden (1973). The coordinates of the gravity stations were obtained with differential positioning using two Wild System-200 geodetic GPS stations with Wild-299 sensors (DGPS methodology using the Rapid Static technique). An observation point was occupied for as long as required for the ambiguities to be resolved during post processing. Computations were carried out with the of SKI-PRO software by Leica Geosystems AG. The DGPS technique affords a positioning accuracy of a few millimetres in both the horizontal coordinates (which is at least one order of magnitude better that required by the gravity method) and the vertical coordinate (in which the gravity method is particularly sensitive). It has been argued (e.g. Featherstone 1995, Featherstone and Dentith 1997) that the highest accuracy affordable for the vertical coordinate is of the order of a few centimetres. In our case the short length of the baselines and observation loops ensures small adjustment errors, of the order of a few millimetres. At any rate, and considering the scale of the survey, inaccuracies of the order of a few centimetres would have insignificant consequences, or at least not worse than the conventional positioning methods.

Digital Elevation Model (DEM): In order to study the morphological characteristics of the study area and perform the necessary topographic corrections a DEM of the study area was compiled, based on high resolution scanned images of the 1:5,000 scale topographic maps issued by the Hellenic Army Geographical Survey (HAGS). The DEM was constructed by digitizing contour lines and transforming their horizontal coordinates to the Hellenic Geodetic Reference System (HGRS-87). The area is covered by 10 topographic maps of this scale. The adopted procedure allows a resolution as fine as the nominal error in the horizontal direction $( \pm 2 \mathrm{~m})$. In order to maintain a healthy tradeoff between data volume and desired resolution, the digitized and transformed contours were interpolated onto a HGRS- 87 grid of spacing $25 \times 25 \mathrm{~m}$. The DEM is shown in Figure 3, along with additional information (hydrographic network and simplified geology).

Terrain correction The terrain correction was calculated for a radius up to $21 \mathrm{~km}$ around each station. The calculation was performed for circular zones with outer radii $50 \mathrm{~m}, 1500 \mathrm{~m}$ and $21 \mathrm{~km}$ respectively. For the near-field terrain effects (within a circle of radius of $50 \mathrm{~m}$ ) a Hammer zone chart (Hammer 1939) was used and the calculation was carried out in situ during fieldwork. The correction for the intermediate $(50-1500 \mathrm{~m})$ and outer $(1.5-21 \mathrm{~km})$ zones was based on the DEM and calculations were carried out with the algorithm originally described by Swain and Khan (1978) and Lagios (1979), as modified by S. Chailas to calculate the gravity effect of topography using vertical prisms (planar model since the deviation between planar and spherical is insignificant at such radii).

\section{Gravity Anomaly Maps}

After applying the necessary reductions, the standard Bouguer anomaly was calculated using a density $2.67 \mathrm{gr} / \mathrm{cm}^{3}$. The resulting Bouguer anomaly map is presented in Figure 4 . The Bouguer anomaly values range between 49.5 and $61 \mathrm{mGal}$ and exhibit a strong westward downhill trend (regional field).

Local scale anomalies are evident in the map suggesting the existence of local structures covered by the post-Alpine formations. In order to interpret the Bouguer anomaly map in terms of local structures, it is necessary to remove the regional field component. To do this effectively, use was 


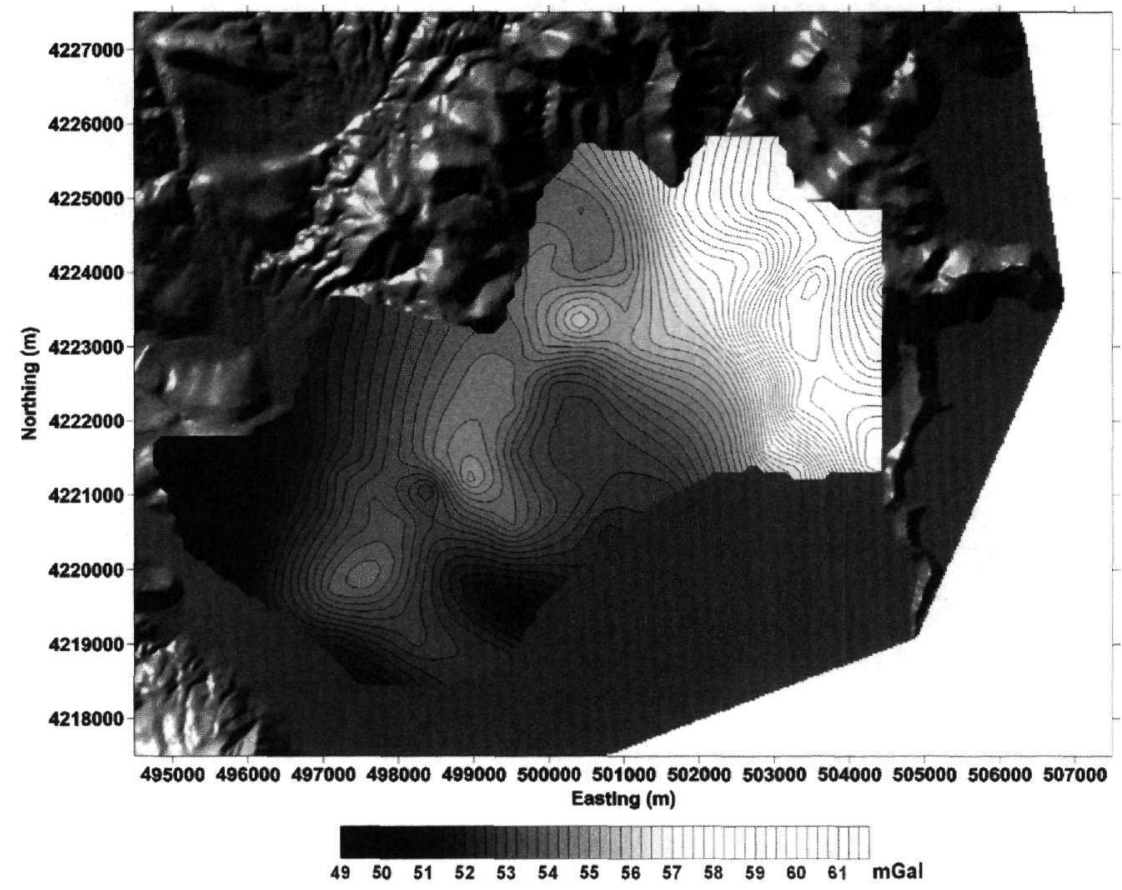

Figure 4 - Bouguer Gravity Anomaly Map (density $2.67 \mathrm{gr} / \mathrm{mm}^{3}$ ) of the Marathon Basin area overlaid on the shaded relief of the topography

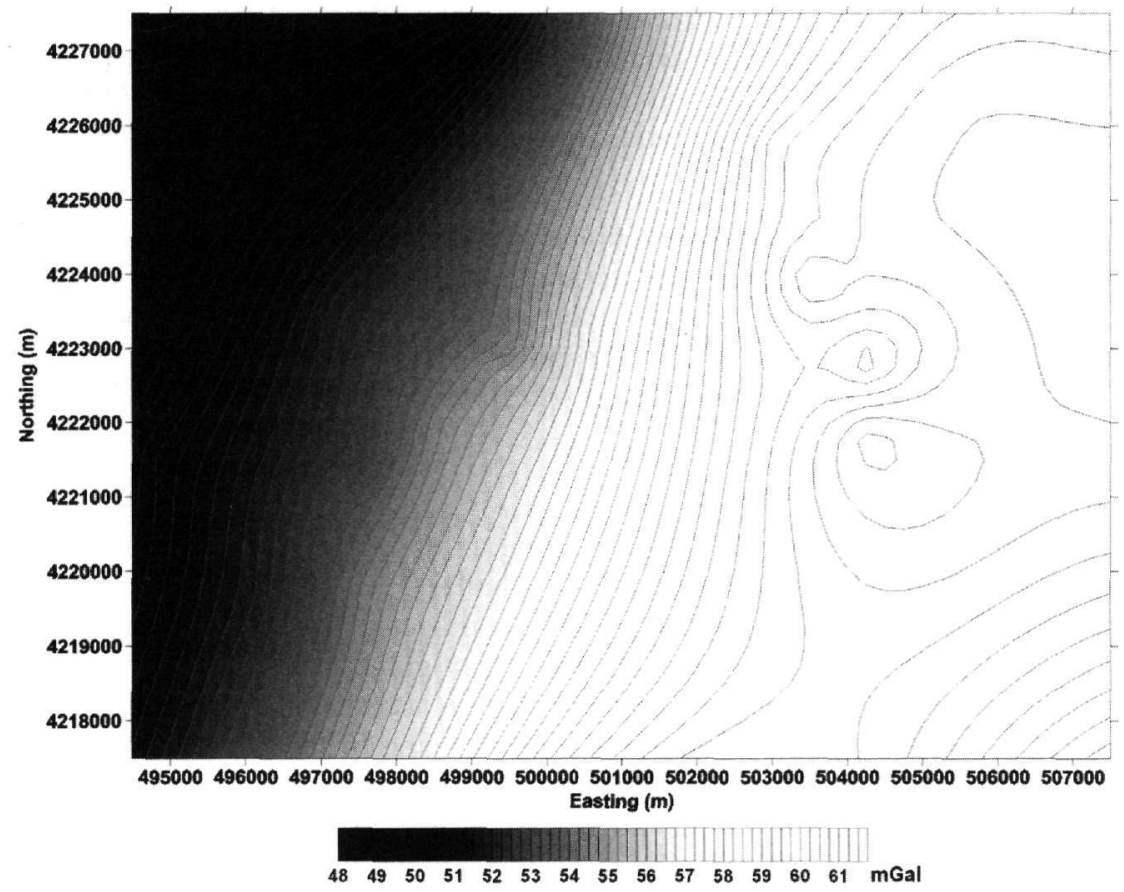

Figure 5 - Regional Gravity Anomaly Map of the Marathon Basin area 


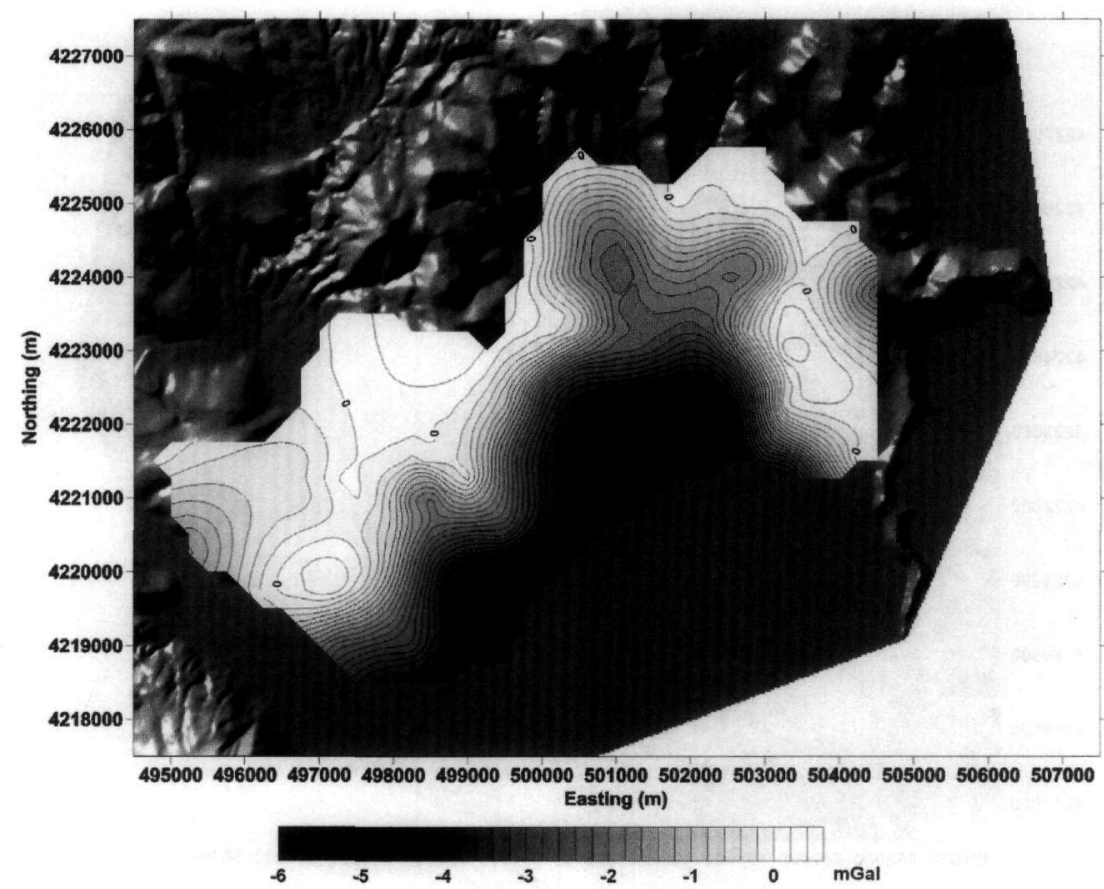

Figure 6 - Residual Gravity Anomaly Map of the Marathon Basin area overlaid on the shaded relief of the topography

made of the gravity data bank available by Lagios et al. (1996), which was constructed by enriching and recompiling the original gravity data of Makris and Stavrou (1984). The spatial density of gravity stations in this data bank is less that one per $\mathrm{km}^{2}$, but their number and distribution is nevertheless sufficient to constrain the regional field. Accordingly, the Marathon gravity data set was spatially extended with data extracted from the data bank. The regional field (Fig. 5) was then interpolated from this spatially extended data set. The resulting residual anomaly map is presented in Figure 6.

The residual anomaly values range between 0 and $6 \mathrm{mGal}$. They exhibit a general NW-SE trend and significant fine structure at the area of Kato Souli; the residual anomaly is generally dipping to the SE direction, showing a step-like change in the areas of Kato Souli and Oinois River. It is also apparent that the boundaries of the Basin are quite well defined by the abrupt change of the gradient of the anomalous field along the Alpine - Post Alpine boundary.

\section{Inversion}

The residual anomaly of Figure 6 was inverted using an unpublished algorithm developed at the Department of Geophysics and Geothermy (S. Chailas), which is based on the theory of Radhakrishna Murthy et al. (1989, 1990). In this approach, any three-dimensional geological object can be approximated (descretized) with some configuration of adjacent vertical polygonal laminae, whose gravity effect at a measurement station is calculated by line integration. The discretization of the object can only be as fine as the spacing of the gravity anomaly grid. If the horizontal dimensions of the object are smaller than the dimensions of the grid, the object is treated as having zero thickness in the area outside its physical boundaries. The inversion procedure is iterative and uses Bott's (1960) method to readjust the thickness (or vertical extent) of the model in order to home-in to a solution. 
In this implementation, the post-Alpine formations of the Marathon Basin were considered to be a single object with a density contrast of $-0.5 \mathrm{gr} / \mathrm{cm}^{3}$ against the basement rocks. This contrast is considered plausible and reliable according to density measurements performed by Goumas (2006) in the broader area of Attica. The upper surface of the model (topography of the post-Alpine formations) was kept constant and the lower surface (topography of the Alpine basement) was allowed to vary. The results (topography of the basement) are shown in Figure 7, combined with the known topography (i.e. the DEM) of the surrounding area. The structure of the basin is well resolved and exhibits an intricate pattern of structural features, whose interpretation will be attempted forthwith.

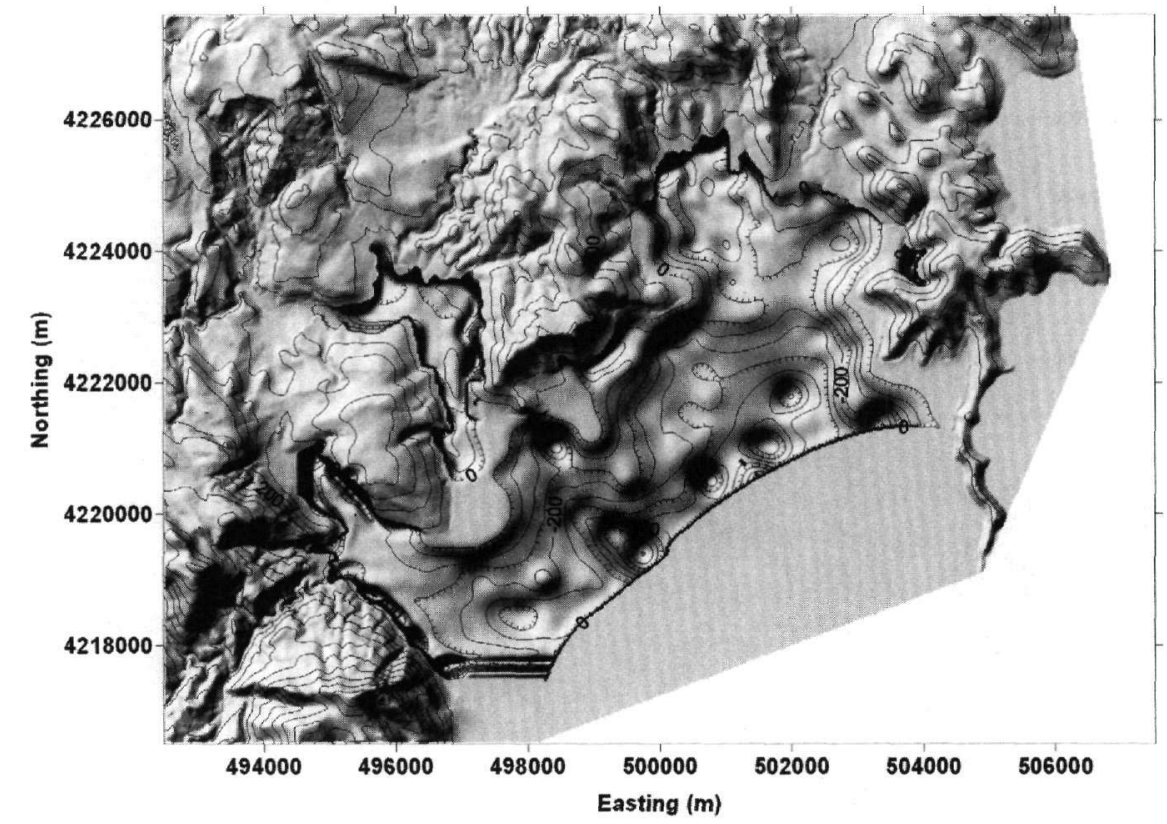

Figure 7 -3D Model of the Marathon Basin basement relief combined with the detailed shaded relief of the surrounding area topography.

\section{Discussion and Conclusions}

The interpretation of the results of Figure 7 is facilitated by superimposing the combined DEM/ basement topography on a geo-referenced image of the 1:50000 standard issue IGME geological maps. The results are shown in Figure 8.

To proceed, consider that: (a) Inasmuch as the significant or abrupt changes in basement topography can be interpreted in terms of fault escarpments, and, (b) active faults in hard rock environments usually produce elongate gorges or ravines, then, the linear continuity of ravines and escarpments (in the sense that lateral extrapolation of buried escarpments coincides with ravines and vice versa), is a potent indicator of the presence of major faults. This becomes a certainty when the extrapolated buried escarpment coincides with mapped faults.

Application of this postulate allows drafting of a number of NE-SW faults (marked with X in Fig. 8). These are apparently normal, causing the basement to experience stepwise depression in the NW-SE direction and to a maximum detectable depth of $\sim 450 \mathrm{~m}$. However, there's much more information available in the data. Application of the same postulate indicates the existence of significant NW-SE faulting structures (marked with R1 in Figure 8), the most prominent of which coincides with the valley of Oinois river in the mid-west region of the study area. A similar fault is postulated to exist at the eastern end of the Basin, along the Mt Drakonera - Mt Megali Koryfi 
uplands. Mapped faults with the same orientation but opposite throw are observed at eastern downhill side of the uplands, implying that the Drakonera - Megali Koryfi chain is a horst-like structure. In addition to these faults, there are minor faulting features with orientation $\mathrm{N} 290^{\circ}-$ $\mathrm{N} 300^{\circ}$, mainly mapped by surface geological surveys, rather than directly observable in the (inverted) gravity data. In Figure 8, the probable location of such a feature is indicated with a broken line and marked with P. It is also possible to observe a prominent E-W lineament (indicated with a dash-dot line) along the line Marathon - Mt. Strati - Mt Drakonera - cape Pounta. Notably, this lineament is associated with a ridge in the morphology of the basement between Mt Strati and Mt Drakonera.

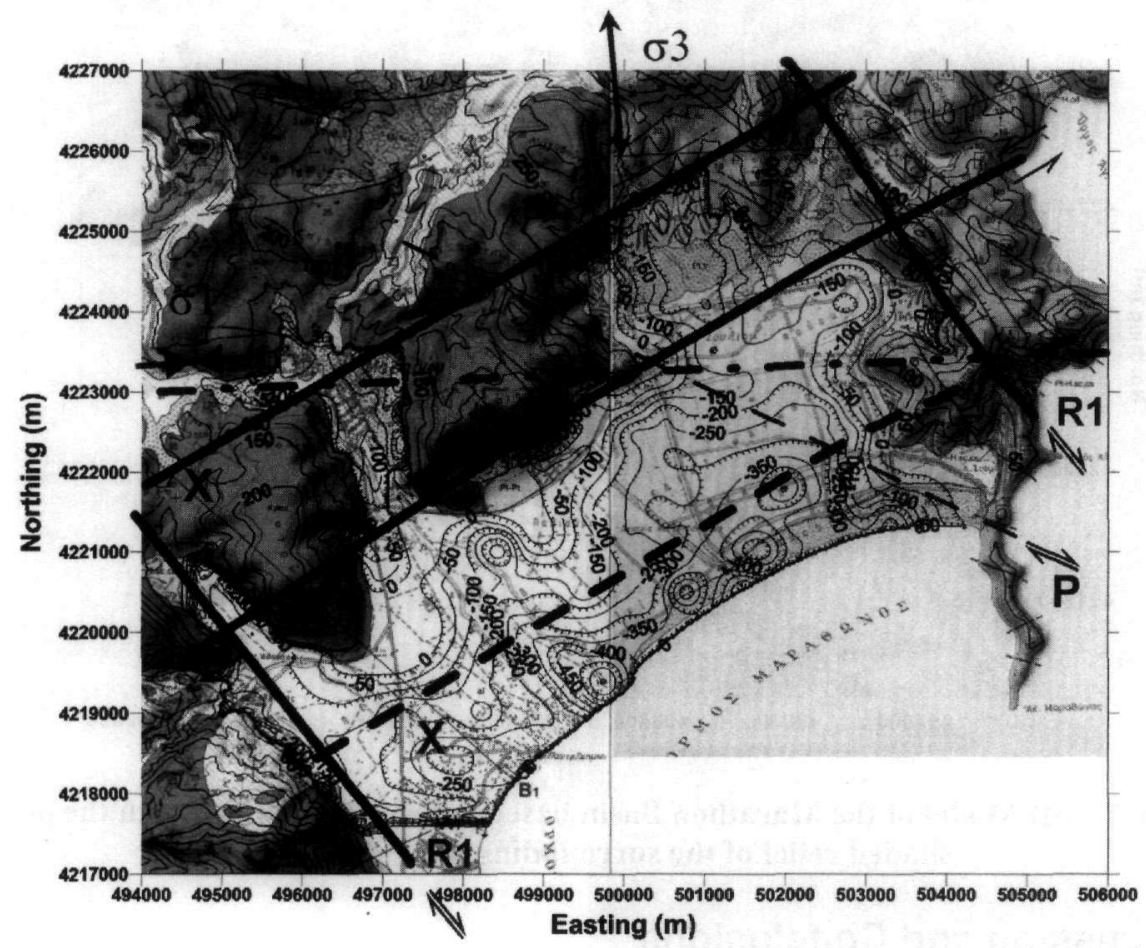

Figure 8 - The combined DEM/ basement topography overlaid on a geo-referenced image of the 1:50000 standard issue IGME geological map. Interpreted major faults are marked with continuous and broken black lines (see main text for details). The dash-dot line marks a line of no shear. $\sigma_{1}$ and $\sigma_{3}$ are the (out of scale) horizontal projections of the stress field thought to have produced the faulting pattern

It appears possible to relate these faulting features in terms of a local Riedel structure. This structure should have originated in response to a predominantly N-S extensional field associated with a small E-W horizontal compressional component, such as to effect a degree of clockwise block rotation. In this view, the NE-SW normal faults correspond to the expected Riedel-X zones, the $\mathrm{N} 290^{\circ}-\mathrm{N} 300^{\circ}$ faults to Riedel-P zones and the NE-SW major faults to the $\mathrm{R}_{1}$ shears. There is evidence of NW-SE lineaments corresponding to $\mathrm{R}_{2}$ shears, but not strong enough as to warrant pointing them out. The configuration of the observed faulting structures fits remarkably well with what is theoretically expected for the deformation of a granular solid through Riedel shears. Let also be noted that the combination of N-S extension with block rotation in a Riedel-structure is also expected to form local anticlinal and synclinal structures, which endow the area with its rather complicated morphology. Two such structures may actually correspond to Mt Strati (anticlinal) and Kato Souli plain (synclinal). 
It has hitherto been accepted that the basement of the Marathon basin comprises marbles located at a depth of 40-55 m below surface near the margins of the basin and up to $60 \mathrm{~m}$ at the central parts, and that a karstic aquifer exists within these marbles (Melissaris and Stavropoulos 1999, Stavropoulos and Tzima 2001, Margonis 2006). This understanding was mainly founded on interpretations of geoelectric (Schlumberger) data, particularly those by Melissaris and Stavropoulos (1999). The existence of marbles at such depths has not been verified by drilling; the deepest boreholes in the area do not exceed $20 \mathrm{~m}$ (e.g. Margonis 2006). Our work has conclusively shown that this cannot be the case: the basement is located at definitely greater depths and that its morphology is intricate and tectonically controlled. There is no karstic aquifer at depths of $50-60$ $\mathrm{m}$ below the Marathon Basin and scrutiny may show that the 'shallow' basement assumption was based on misinterpretation of the Shlumberger data. Instead, we probably have to deal with a system of sedimentary aquifers possibly communicating through the intricate tectonic fabric. In a final note, consider that the multiple intersections of multiple faults is expected to form a permeable network, presumably responsible for the observed salination of the local aquifer system; if this is correct, the NE-SW major normal faults may the most significant contributor to this effect.

\section{Acknowledgments}

This work was financially supported by the European Social Fund and Greek National Resources (EPEAEK II), PYTHAGORAS. The authors acknowledge the assistance of Ms Eleni Partheniou and Ms Eleftheria Drosopoulou in the fieldwork and in data reduction.

\section{References}

Boetechtel, J., and Papadeas, G., 1968. Tectonic aereal interpretation in the Mediterranean region exemplified by the metamorphic series at eastern Greece, near Marathon, Photogrammetria, 26, 201-210.

Bott, M.H.P., 1960. The use of rapid digital computing methods for direct gravity interpretation of sedimentary basins, Geoph. J.R. astr. Soc., 38(4), 253-264.

Cartwright, D.E., and Edden, A.C., 1973. Corrected tables of tidal harmonics, Geoph. J.R. astr. Soc., 33, 253-264.

Cartwright, D.E., and Tayler, R.J., 1971. New computations of the tide-generating potential, Geoph. J.R. astr. Soc., 23, 45-74.

Featherstone, W. E., and Dentith, M. C., 1997. A geodetic approach to gravity data reduction for geophysics, Computers \& Geosciences, 23(10), 1063-1070.

Featherstone, W. E., 1995. The Global Positioning System and its use in geophysical exploration, Exploration Geophysics, 26(1), 1-18

Goumas, G., 2006. Exploring the structure of Thriasion Plain with geophysical methods, MSc Thesis, Faculty of Geology and Geoenvironment, University of Athens.

Hammer, S., 1939. Terrain corrections for gravimeter stations, Geophysics, 4, 184-194.

Lagios, E., 1979. Gravity and other geophysical studies relating to the crustal structure of southeast Scotland, PhD Thesis, Edinburgh University, 309pp.

Lagios, E., Chailas, S., and Hipkin, R.G., 1996. Newly Compiled Gravity and Topographic Data Banks of Greece, Geoph. J. Intern. 126, 287-290.

Lozios, S., 1991. Microtectonic observations in the metamorphic system of the Varnavas - Ramnounta area, NE Attica, Bull. Geol. Soc. Greece, 25(1), 439-453. (in Greek)

Lozios, S., 1993. Tectonic analysis of the metamorphic formations of NE Attica, PHD Thesis, University of Athens, 299pp. (in Greek) 
Makris, J., and Stavrou, A., 1984. Compilation of gravity maps of Greece, Technical Report, Institute of Geological and Mining Exploration, Athens.

Margonis, S., Syridis, G., Psilovikos, A.R., Trontsios, G. Steinhauer, G., Vouvalidis, K., and Mouzouris, G, 2002. The evolution of the natural environment in the area of Schinias wetlands, Marathon, from the ancient era to date, Proceedings, 6th Panhellenic Geographical Congress, Thessaloniki, October 2002, 159-165. (in Greek)

Margonis, S., 2006. Investigation of the environmental processes of the evolution of the Marathon Plain wetlands during the Holocene using Geographical Information Systems (G.I.S.), PhD Thesis, Aristotle University of Thessaloniki, 164pp. (in Greek)

Maroukian, H., Zamani, A., and Pavlopoulos, K., 1993. Coastal retreat in the Plain of Marathon (east Attica), Greece: cause and effects, Geologica Balcanica, 23, 67-71.

Melissaris, P., and Stavropoulos, X., 1999. Hydrogeological Study of the Marathon Plain, Attica, Department of Geology - Hydrogeology, Ministry of Agricultural Development. (in Greek)

Mettos, A., 1992. Geological and Palaeogeographical study of the Terrestrial Neogene and Quartenary formations of NE Attica and SE Beotea, PhD Thesis, University of Athens, $259 \mathrm{pp}$. (in Greek)

Morelli, C., Gantar, C, Honkasalo, T., McConnell. R. K., Tanner, J. G., Szabo, B., Uotila, U., and Whalen, C.T., 1974. The international gravity standardisation net (I.G.S.N. 71), IAG Specia 1 Publication No. 4, 194pp.

Pavlopoulos, K., Karkanas, P., Triantaphyllou, M., Karymbalis, E., Tsourou, Th., and Palyvos, N., 2006. Paleoenvironmental Evolution of the Coastal Plain of Marathon, Greece, during the Late Holocene: Depositional Environment, Climate, and Sea Level Changes, Journal of Coastal Research, 22 (2), 424-438.

Radhakrishna Murthy, I.V., Rama Rao, P., and Jagannardha Rao, S., 1990. The density difference and generalized programms for two and three-dimensional gravity modeling., Computers \& Geosciences, 16(3), 277-287.

Radhakrishna Murthy, I.V., Rama Rao, P., and Ramakrishna, P., 1989. Gravity Anomalies of Three-dimensional Bodies with Variable Density Contrast, PAGEOPH, 130(4), 711-719.

Seni, A, Kapsimalis V, and Pavlopoulos, K., 2004. Determination of recent geomorphologic changes in the Marathonas coastal plain (Attica, Greece), using geographical information systems, 6th Panhellenic Geographical Congress, Mytilini, Greece, October 2004. (in Greek, available at http://www.ath.aegean.gr/srcosmos)

Stavropoulos, X., and Tzima, M., 2001. Investigation related to the salt intrusion mechanisms of Kato Souli springs, Marathonas, Attiki, Bull. Geol. Soc. Greece, XXXIV/5, 1967-1972.

Swain, C.J., and Khan, M.A., 1977. A catalogue of gravity data in Kenya, Leicester University Publications. 